\title{
Letter to the Editor: Validity of the bolton index using cone-beam computed tomography (CBCT); Methodological mistake
}

\author{
Siamak Sabour ${ }^{1}$, Elahe Vahid-Dastjerdi ${ }^{2}$
}

${ }^{1} \mathrm{MD}, \mathrm{MSc}$, DSc, PhD Department of Clinical Epidemiology, Shahid Beheshti University of Medical Sciences, Tehran, Iran

${ }^{2}$ Faculty of Dentistry, Shahid Beheshti University of Medical Sciences, Tehran, Iran

Correspondence:

Department of Clinical Epidemiology

Shahid Beheshti University of Medical Sciences

PC: 1983969411, Tehran, Iran

s.sabour@sbmu.ac.ir

Sabour S, Vahid-Dastjerdi E. Validity of the bolton index using conebeam computed tomography (CBCT); Methodological mistake. Med Oral Patol Oral Cir Bucal. 2013 Sep 1;18 (5):e822-3.

Received: 11/07/2012

Accepted: 14/11/2012

http://www.medicinaoral.com/medoralfree01/v18i5/medoralv18i5p822.pdf

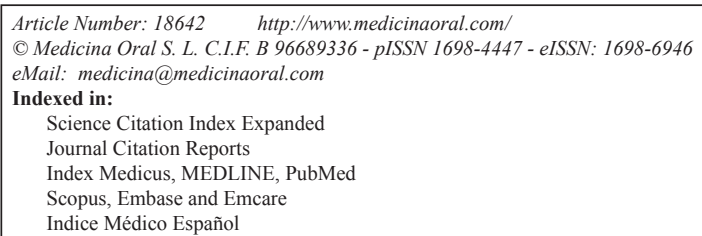

We were interested to read the paper by Tarazona B, and colleagues published in the May 2012 issue of Med Oral Patol Oral Cir Bucal. The authors aimed to evaluate the reliability and reproducibility of calculating the Bolton Index using cone-beam computed tomography (CBCT), and to compare this with measurements obtained using the 2D Digital Method. They report by determining the regression lines for both measurement methods, as well as the difference between both of their values, the two methods are shown to be comparable, despite the fact that the measurements analysed presented statistically significant differences. (1) Why did the authors not use well known statistical tests as Sensitivity, Specificity, positive predictive value (PPV), negative predictive value (NPV) to test the validity of the Bolton Index? $(2,3)$ or use other methods such as likelihood ratio positive and negative (LR+ \& LR-)? (2,3) It is good to know that reliability (precision) and validity (accuracy) are two completely different methodological issues evaluating by different tests (2-4). As the authors point out in their conclusion; the threedimensional models obtained from the $\mathrm{CBCT}$ are as accurate and reproducible as the digital models obtained from the plaster study casts for calculating the Bolton Index. Such conclusion is just misinterpretation of the results and should really be avoided in clinical researches, otherwise; we will face with misdiagnosis and mismanagement of the patients.

Key words: Validity, cone-beam computed tomography, mistake. 


\section{References}

1. Tarazona B, Llamas JM, Cibrián R, Gandía JL, Paredes V. Evaluation of the validity of the Bolton Index using cone-beam computed tomography (CBCT). Med Oral Patol Oral Cir Bucal. 2012;17:e87883.

2. Formica MK, McAlindon TE, Lash TL, Demissie S, Rosenberg L. Validity of self-reported rheumatoid arthritis in a large cohort: results from the Black Women's Health Study. Arthritis Care Res (Hoboken). 2010;62:235-41.

3. Johnson JA, Lee A, Vinson D, Seale JP. Use of AUDIT-based measures to identify unhealthy alcohol use and alcohol dependence in primary care: a validation study. Alcohol Clin Exp Res. 2013;37Supp11:E253-9.

4. Bland JM, Altman DG. Agreed statistics: measurement method comparison, Anesthesiology. 2012;116:182-5.

\section{Competing Interests Statement}

The first authors (Siamak Sabour): methodology and statistics

The second authors (Elahe Vahid Dastjerdi): clinical aspect and implication of the study result. 